\title{
Different Phenotypes, Similar Genomes: Three Newly Sequenced Fusarium fujikuroi Strains Induce Different Symptoms in Rice Depending on Temperature
}

\author{
Edoardo Piombo, ${ }^{1,2}$ Pietro Bosio, ${ }^{1}$ Alberto Acquadro, ${ }^{1}$ Pamela Abbruscato, ${ }^{3}$ and Davide Spadaro ${ }^{1,2, \dagger}$ \\ ${ }^{1}$ Department of Agricultural, Forestry and Food Sciences, University of Torino, Grugliasco, Turin 10095, Italy \\ ${ }^{2}$ Centre of Competence for the Innovation in the Agroenvironmental Sector, University of Torino, Grugliasco, Turin 10095, Italy \\ ${ }^{3}$ Parco Tecnologico Padano, Lodi, Lombardy 26900, Italy \\ Accepted for publication 10 November 2019.
}

\begin{abstract}
Bakanae, caused by the hemibiotrophic fungus Fusarium fujikuroi, is one of the most important diseases of rice and is attributed to up to $75 \%$ of losses, depending on the strain and environmental conditions. Some strains cause elongation and thin leaves, whereas others induce stunting and chlorotic seedlings. Differences in symptoms are attributed to genetic differences in the strains. F. fujikuroi strains Augusto2, CSV1, and I1.3 were sequenced with Illumina MiSeq, and pathogenicity trials were conducted on rice cultivar Galileo, which is susceptible to bakanae. By performing gene prediction, single nucleotide polymorphism (SNP) calling, and structural variant analysis with a reference genome, we show

21,887 SNPs between them, but they differed in virulence, reaction to temperature, induced symptoms, colony morphology and color, growth speed, fumonisin, and gibberellin production. Genes potentially involved in the shift in phenotype were identified. Furthermore, we show how temperature variation may result in different symptoms even in rice plants inoculated with the same F. fujikuroi strain. Moreover, all of the F. fujikuroi strains became more virulent at higher temperatures. Significant differences were likewise observed in gibberellic acid production and in the expression of both fungal and plant gibberellin biosynthetic genes.
\end{abstract} how an extremely limited number of polymorphisms in genes not commonly associated with bakanae disease can cause strong differences in phenotype. CSV1 and Augusto2 were particularly close, with only
Keywords: bakanae, Fusarium fujikuroi, genomics, Illumina sequencing, rice
Bakanae, caused by the hemibiotrophic fungal pathogen Fusarium fujikuroi [teleomorph Gibberella fujikuroi (Sawada) Ito in Ito \& K. Kimura], is one of the most important diseases of rice (Carter et al. 2008; Desjardins et al. 1997). Crop losses attributable to bakanae are largely dependent on the climate and rice cultivar, varying from 3 to $75 \%$ in certain cases (Saremi et al. 2008).

Originally observed in Japan in 1828, bakanae disease is now present in several countries in the United States, Europe, Asia, and Africa. Researchers have used disparate approaches to investigate how rice plants can resist the disease, from RNA sequencing to quantitative trait loci mapping (Fiyaz et al. 2016; Ji et al. 2018; Matić et al. 2016); despite this, no rice cultivar showing a complete resistance to bakanae has been developed to date, and there is still limited knowledge of the mechanisms of resistance (Bagga and Kumar 2000; Desjardins et al. 2000).

The $F$. fujikuroi pathogen commonly induces symptoms such as abnormal height, thin leaves, and grains that are entirely or partially empty, mainly as a result of gibberellin production (Niehaus et al. 2017). F. fujikuroi is also able to increase the production of these

†Corresponding author: D. Spadaro; davide.spadaro@unito.it

Funding: This project received funding from the European Union Horizon 2020 research and innovation program under grant agreement 634179 ("Effective Management of Pests and Harmful Alien Species-Integrated Solutions" [EMPHASIS]) and from the AGER Foundation under grant 2010-2369 ("Integrated Genetic and Genomic Approaches for New Italian Rice Breeding Strategies" [RISINNOVA])

*The $\boldsymbol{e}$-Xtra logo stands for "electronic extra" and indicates that three supplementary figures, five supplementary tables, and three supplementary data files are published online.

The author(s) declare no conflict of interest.

Modified: 27 Apr 2020

(C) 2020 The American Phytopathological Society phytohormones by the plant, with less susceptible cultivars showing less gibberellin production and a reduced expression of their biosynthetic gene cluster, compared with highly susceptible cultivars (Kim et al. 2018; Matić et al. 2016; Siciliano et al. 2015). Despite this, there are also reports of strains inducing stunted and chlorotic seedlings (Gupta et al. 2015), often followed by root and crown rot (Amoah et al. 1995; Karov et al. 2009). Because of these differences, F. fujikuroi strains are divided into two pathotypes (Niehaus et al. 2017).

Besides their ability to induce bakanae disease, some strains of F. fujikuroi are also known for the production of fumonisins, neurotoxic mycotoxins (Desjardins et al. 1997; Wulff et al. 2010). The most studied fumonisin, FB1, is known to cause equine leukoencephalomalacia and porcine pulmonary edema (Scott 2012), and it has been associated with human esophageal cancer (Chu and Li 1994; Sydenham et al. 1990) and kidney and liver cancer in mice (Creppy 2002).

F. fujikuroi was sequenced for the first time in 2013 (Jeong et al. 2013; Wiemann et al. 2013), but many more strains have since become available (Bashyal et al. 2017; Chiara et al. 2015; Niehaus et al. 2017; Radwan et al. 2018; Urbaniak et al. 2018). This fungus has a genome of around $45 \mathrm{Mb}$, divided among 12 chromosomes, with repetitive elements constituting $<1 \%$ of the total. The gene content on average varies between 13,000 and 15,000 genes, including around 1,200 genes encoding for secreted proteins.

Besides gibberellins, the fungus is able to produce a wide array of secondary metabolites, including both mycotoxins, such as fumonisins, fusaric acid, and fusarins (Bacon et al. 1996; Barrero et al. 1991; Desjardins et al. 1997), and pigments, like bikaverin and fusarubins (Balan et al. 1970; Studt et al. 2012). Forty-seven putative gene clusters for secondary metabolites were found in the reference genome of $F$. fujikuroi (Wiemann et al. 2013), and a number of these have been characterized (Janevska and Tudzynski 
2018). A number of global and local regulators control the production of secondary metabolites, but many are also able to regulate gibberellin production and therefore pathogenicity. These include the global nitrogen regulators area (Tudzynski et al. 1999) and areb (Pfannmüller et al. 2017) and the component of the velvet complex lael (Niehaus et al. 2018).

F. fujikuroi shows complete synteny in the fumonisin cluster with $F$. verticillioides and $F$. oxysporum (Wiemann et al. 2013), despite reduced production of these molecules (Stępień et al. 2011; Wulff et al. 2010) compared with the above-mentioned species. However, in F. fujikuroi, the ability to produce fumonisins and the quantity produced can vary significantly depending on the genotype and the environment (Matić et al. 2013).

Temperature is one of the most important factors influencing both the virulence of $F$. fujikuroi strains and the production of fumonisins but, notwithstanding, there are few works investigating its effect on the rice-F. fujikuroi pathosystem (Matić et al. 2017; Saremi and Farrokhi 2004).

This work aimed to use a combination of high-throughput sequencing, comparative genomics, chemical analyses, and molecular biology to investigate the effect of temperature on virulence and secondary metabolite production in three $F$. fujikuroi strains showing different phenotypes. The strains considered were Augusto2, CSV1, and I1.3, all isolated from infected rice plants in Northern Italy (Amatulli et al. 2010).

\section{MATERIALS AND METHODS}

Microorganisms and seeds. The Augusto2, CSV1, and I1.3 $F$. fujikuroi strains, previously isolated from diseased rice plants in Piedmont (Amatulli et al. 2010) and maintained in the Centre of Competence for the Innovation in the Agroenvironmental Sector microorganism collection, were grown on sterile potato dextrose broth (PDB) for 10 days at $23^{\circ} \mathrm{C}$. Afterward, the suspensions were filtered through sterile gauze, centrifuged for $20 \mathrm{~min}$ at 6,000 rpm, and resuspended in Ringer solution. The Burker chamber was then used to obtain concentrations of $10^{5}$ conidia $/ \mathrm{ml}$. Galileo rice seeds, susceptible to bakanae disease (Amatulli et al. 2010), were thermally treated by dipping in water at $60^{\circ} \mathrm{C}$ for $5 \mathrm{~min}$, immersed in a solution of $1 \% \mathrm{NaClO}$ for $2 \mathrm{~min}$, and then washed three times with sterile water for $5 \mathrm{~min}$. The seeds were then divided and immersed in the conidial suspension of the different strains and kept in agitation for $30 \mathrm{~min}$.

Pathogenicity trials. After drying for $24 \mathrm{~h}$ on sterile paper, the seeds were sown in sterilized substrates (70\% white peat and $30 \%$ clay, with $\mathrm{pH}$ between 5.5 and 6). The nitrogen content was between 110 and $190 \mathrm{mg} / \mathrm{liter}, \mathrm{P}_{2} \mathrm{O}_{5}$ was between 140 and $230 \mathrm{mg} / \mathrm{liter}$, and $\mathrm{K}_{2} \mathrm{O}$ was between 170 and $280 \mathrm{mg} / \mathrm{liter}$. The plants were grown in two growth chambers: one was kept at $22^{\circ} \mathrm{C}$ and the other at $31^{\circ} \mathrm{C}$. Disease symptoms were monitored weekly starting 1 week postgermination (wpg). A disease index score was assigned as follows, depending on the visible symptoms: 0 , healthy plant; 1 , reduced dimension, chlorotic leaves; 2 , internode elongation, significant yellowing, significant dwarfism; 3, necrosis of the crown; and 4, dead or not-germinated plant. Each strain was tested on four replicates of 30 plants. Four replicates of 30 uninoculated plants were used as the control. The experiment was performed twice.

RNA extraction and quantitative PCR. RNA was extracted from the basal half of the shoot of plants inoculated with each of the strains, as well as from control plants, by using the RNeasy kit (Qiagen, Hilden, Germany). The extracted RNA was quantified by a NanoDrop spectrophotometer (Thermo Fisher Scientific, Waltham, MA) and purified using the TURBO DNA-free kit (Ambion, Foster City, CA). The samples were then checked for DNA contamination by PCR. The gene used was the rice elongation factor 1-alpha. After the sample purity was verified, the RNA was used to obtain the cDNA by using the iScript cDNA synthesis kit (Bio-Rad, Hercules, CA). The samples were then used in real-time quantitative PCR (StepOnePlus; Applied Biosystems, Foster City, CA), with primers for fuml (fumonisin gene cluster polyketide synthase, F. fujikuroi), fum21 (fumonisin gene cluster transcription factor, F. fujikuroi), cps/ks (gibberellin gene cluster ent-copalyl diphosphate synthase ent-kaurene synthase, F. fujikuroi), and gib20oxl (Gibberellin 20 oxidase 1 , rice). The PCR mix was composed of $5 \mu$ l of Applied Biosystems SYBR Green Power Mix, $2 \mu \mathrm{l}$ of cDNA, $0.15 \mu \mathrm{l}$ of each primer $(10 \mu \mathrm{M})$ and $2.4 \mu \mathrm{l}$ of nuclease-free water (Tudzynski and Hölter 1998). The thermal cycler protocol was as follows: $95^{\circ} \mathrm{C}$ for $10 \mathrm{~min}$, followed by 40 cycles at $95^{\circ} \mathrm{C}$ for $15 \mathrm{~s}$ and $60^{\circ} \mathrm{C}$ for $60 \mathrm{~s}$ ), and $95^{\circ} \mathrm{C}$ for $15 \mathrm{~s}$. The ubiquitin $F$. fujikuroi gene (Wiemann et al. 2013) and the rice elongation factor 1-alpha (Manosalva et al. 2009) were used as housekeeping genes, respectively, for fungal and plant genes. The sequences of the primers used are reported in Supplementary Table S1. The efficiency of the primers used for fum 21 and gib20ox 1 amplification was tested with a standard curve built upon five serial dilutions (1:10).

In vitro assays. Every strain was grown in PDB flasks ( $30 \mathrm{ml}$ of medium) and YES Agar plates. The flasks and the plates were inoculated with $100 \mu \mathrm{l}$ of a solution containing $10^{5}$ conidia/ml, prepared following the same procedure used for the pathogenicity trials. The plates were kept at $24^{\circ} \mathrm{C}$, with a $12 / 12$-h light/dark photoperiod, a light intensity of $1 \mathrm{~cd}$, and a relative luminosity of $55 \mathrm{~cd}$. During the fungal growth in YES Agar, the mycelial diameter was measured and the color and texture were monitored.

Chemical extractions. Samples obtained from the PDB flasks were filtered to separate the mycelium from the growth medium. The mycelium was weighed $(500 \mathrm{mg})$ and extracted with $1 \mathrm{ml}$ of methanol/water $(8: 2 \mathrm{vol} / \mathrm{vol})$ for $1 \mathrm{~h}$ in an ultrasonic bath. The supernatant was centrifuged and filtered with 0.45 - $\mu \mathrm{m}$ filters, after which it was placed in vials for high-performance liquid chromatography (HPLC) analysis. Regarding the YES Agar plates, the extraction was carried out on the whole plates with $3 \mathrm{ml}$ of methanol. The solvent was spread on the whole surface and the mycelium was scratched and brought to suspension. The extract was then placed in tubes and concentrated Concentrator 5301 (Eppendorf, Hamburg, Germany). The dried residue was dissolved in methanol/water $(1: 1 \mathrm{vol} / \mathrm{vol})$ and placed in vials for HPLC analysis. Similar to the procedure used for mycelia, $500 \mathrm{mg}$ of the in vivo sample was extracted with $1 \mathrm{ml}$ of methanol/water $(8: 2 \mathrm{vol} /$ vol) by an ultrasonic bath for $1 \mathrm{~h}$. The supernatant was centrifuged and filtered with $0.45-\mu \mathrm{m}$ filters, after which it was placed in vials.

HPLC-tandem mass spectrometry. Liquid chromatography (LC) was performed with Varian model 212-LC micropumps (Varian, Palo Alto, CA) coupled with Varian ProStar 126 autosampler model 410. A Synergi 4- $\mu$ m Fusion-RP 80A analytical column (100× $2.0 \mathrm{~mm}$; Phenomenex, Castel Maggiore, Italy) was used coupled with Fusion-RP $(4 \times 2.0 \mathrm{~mm})$ security guard for LC separation. The chromatographic conditions were as follows: column temperature at $45^{\circ} \mathrm{C}$ and a mobile phase consisting of eluent $\mathrm{A}(\mathrm{HCOOH} 0.05 \%$ in $\left.\mathrm{H}_{2} \mathrm{O}\right)$ and eluent $\mathrm{B}(\mathrm{CH} 3 \mathrm{CN})$. A gradient elution was applied as follows: from 0 to $20 \%$ of B in $5 \mathrm{~min}$, from 20 to $80 \%$ of B in $15 \mathrm{~min}$, and from 80 to $100 \%$ of $\mathrm{B}$ in $1 \mathrm{~min}$. Five minutes of postrun were necessary for column conditioning before the subsequent injection. The injection volume was $20 \mu \mathrm{l}$, and the flow speed was $200 \mu \mathrm{l} / \mathrm{min}$.

The triple quadrupole mass spectrometer (Varian 310-MS) was operated in negative/positive electrospray ionization mode to select the tandem mass spectrometry parameters for the analysis of metabolites by multiple reaction monitoring. For the quantification of fumonisin B4, the calibration curve of fumonisin B1 was used because fumonisin B4 currently lacks a specific commercial standard. Two transitions were selected for each compound as follows: GA3, $345>214$ (collision energy [CE] $14 \mathrm{eV}$ ) and $345>$ 143 (CE $30 \mathrm{eV})$; FB1, $722>334$ (CE $38 \mathrm{eV})$ and $722>352$ (CE 34 $\mathrm{eV})$; FB2/FB3, $706>336(\mathrm{CE} 36 \mathrm{eV})$ and $706>354(\mathrm{CE} 34 \mathrm{eV})$; and FB4, $690>338(\mathrm{CE} 30 \mathrm{eV})$ and $690>320(\mathrm{CE} 30 \mathrm{eV})$. The collision gas (argon) pressure was set at 2 mbar for all of the experiments.

Sequencing, assembly, and analysis. F. fujikuroi strains Augusto2, CSV1, and I1.3 were sequenced by Parco Tecnologico 
Padano using a next-generation Illumina MiSeq sequencer (Illumina, San Diego, CA). For each strain, a paired end library was generated using the Nextera XT DNA preparation kit (Illumina). For strain I1.3, a mate pair library was also generated using the Nextera Mate Pair kit (Illumina), following the protocols provided by the manufacturer. Libraries were purified by AMPure XP beads and normalized to ensure equal library representation in the pools. Equal volumes of libraries were diluted in the hybridization buffer, heat denatured, and sequenced. The standard phi X control library (Illumina) was spiked into the denatured HCT 116 library. The libraries and phi X mixture were finally loaded into a MiSeq 250 and MiSeq 300-Cycle v2 Reagent Kit (Illumina). Base calling was performed using the Illumina pipeline software. Demultiplexing was done using software program provided by Illumina. Trimming of adapters and removal of ambiguous bases was done using Trim Galore (https://www.bioinformatics.babraham.ac.uk/ projects/trim_galore/), and the resulting cleaned reads were checked with fastqc (https://www.bioinformatics.babraham.ac.uk/projects/ fastqc/) for remaining contamination. For the I1.3 reads, the Scythe program (https://github.com/vsbuffalo/scythe) was also used to remove remaining adapters. Initially, de novo assembly was performed using SPAdes version 3.7.1 (Bankevich et al. 2012), and the obtained assembly was used in a reference-guided approach with IMR-DENOM (http://mtweb.cs.ucl.ac.uk/mus/www/19genomes/IMR-DENOM/), since the low sequencing coverage of Augusto2 and CSV1 made it impossible to obtain a good purely de novo assembly (Supplementary Table S2). The selected mapper used in IMR-DENOM was bwa (Li and Durbin 2009).

Gene prediction. Gene prediction was conducted using MAKER version 2.31.8 (Cantarel et al. 2008). Both predictors augustus version 2.5.5 (Stanke and Waack 2003) and SNAP version 2006-07-28 (http://korflab.ucdavis.edu/software.html) were used. augustus used the "-fusarium" option for gene prediction, whereas SNAP was trained to obtain a file.hmm specific for the three genomes. The necessary repeat libraries were constructed using the basic procedure (http://weatherby.genetics.utah.edu/MAKER/ wiki/index.php/Repeat_Library_Construction-Basic). The external data provided to MAKER and used for the training of SNAP were all of the expressed sequence tags, protein sequences, and transcript sequences of $F$. fujikuroi available in the NCBI database. To launch MAKER, the option "-fix_nucleotides" was used in order to allow the program to work with degenerate nucleotides present in the external data. The option "correct_est_fusion" was also activated in the control files. After the analysis, introns shorter than $10 \mathrm{bp}$, predicted by SNAP, were removed; when this caused a frameshift mutation, the prediction of the gene splicing sites was repeated with augustus version 2.5.5 (Stanke and Waack 2003).

Single nucleotide polymorphism mining. The clean paired end reads of each of the three strains of interest were mapped on the reference genome of $F$. fujikuroi strain IMI 58289 (Wiemann et al. 2013), using bwa version 0.7.12-r1039 (http://bio-bwa.sourceforge. net) with default options. The resulting sam files were converted to sort.bam by samtools version 0.1.19-96b5f2294a (http:// samtools.sourceforge.net/), and they were used for single nucleotide polymorphism (SNP) mining with the following pipeline:

'samtools mpileup -guf reference.fa augusto2.sort.bam CSV1.sort.bam I1.3.sort.bam | bcftools view -cg - | vcfutils.pl varFilter -D 200 -Q 20 - > file.vcf'

Heterozygous SNPs were assumed to be derived from sequencing errors and were excluded from the analysis. The SNPs were mapped on the genome with the program CircosVCF (Drori et al. 2017). The reads of the strains were also mapped, using the same pipeline, on scaffold 005 of F. fujikuroi strain B14 (GenBank FMSL01000005.1), and Tablet (Milne et al. 2013) was used to check whether any reads mapped on the gene FFB14_06372.
Analysis of polymorphisms. SnpEff program version 4.2 (Cingolani et al. 2012) was used to evaluate the impact of the SNPs/ indels identified with the SNP mining after a database for IMI 58289 was built following the manual instructions (http://snpeff.sourceforge. net/SnpEff_manual.html\#databases). Afterward, we checked whether the strains Augusto2, CSV1, and I1.3 presented missense or nonsense polymorphisms in the gibberellin and fumonisin gene clusters or in other genes involved in the biosynthesis regulation of these metabolites (see Supplementary Table S3 for references). The presence of these polymorphisms was then checked in the sort.bam files with the viewer Tablet (Milne et al. 2013). EffectorP 1.0 and 2.0 (Sperschneider et al. 2016) were used on the secreted portion of the F. fujikuroi proteome (Wiemann et al. 2013) to predict putative effector genes, and these genes were also checked for polymorphisms. The impact of polymorphisms of interest was predicted with PROVEAN Protein (Choi and Chan 2015). All of the genes presenting putatively moderate- and high-impact polymorphisms in either Augusto2 or CSV1, but not in both, were identified, according to the evaluation of SNPeff. These genes were annotated with BLAST2GO with default parameters; when they presented GO terms related to regulation of transcription, pathogenesis, or metabolism, the impact of their polymorphisms was predicted with PROVEAN Protein (Choi and Chan 2015).

Structural variant analysis. BreakDancer version 1.3.6 software (Fan et al. 2014) was used to identify structural variants in the genome. Variants with a score of $<80$ were removed, and an original python script (Supplementary Data File S1) was used to identify genes localized in the regions affected by the remaining variations. Genes present in an area involved in a deletion were considered to be affected, as were genes that had the edge of an inversion or a translocation inside their sequence. The script only works on variations involving only one scaffold; therefore, structural variants affecting different chromosomes were checked manually.

Phylogenetic analysis. OrthoFinder version 2.3.3 (Emms and Kelly 2015) was used with the option "-M msa" to obtain a genomewise phylogenetic tree based on single-copy genes, comparing the F. fujikuroi strains Augusto2, CSV1, and I1.3 to several other annotated isolates of the same species. The following strains were used for this analysis (with GenBank accession in parentheses): B20 (GCA_900096605.1), C1995 (GCA_900096645.1), E282 (GCA_900096705.1), FGSC_8932 (GCA_001023045.1), FSU48 (GCA_900096685.1), IMI58289 (GCA_900079805.1), KSU3368 (GCA_001023065.1), KSU X-10626 (GCA_001023035.1), m567 (GCA_900096615.1), MRC2276 (GCA_900096635.1), and NCIM1100 (GCA_900096625.1), with F. oxysporum f. sp. lycopersici 4287 used as the outgroup (GCA_000149955.2). STAG (Emms and Kelly 2018) was used to generate an unrooted species tree, and the root was placed with MEGA (Kumar et al. 1994) between $F$. oxysporum and the $F$. fujikuroi strains.

Comparing Augusto2 and CSV1. Proteinortho version 5.16 (Lechner et al. 2011) was used to identify genes present in either CSV1 or Augusto2, but not in both. Genes unique to CSV1 were then blasted against the genome of Augusto2 and vice versa. Genes with a good blast hit were excluded from the analysis, since they could actually be present in both strains, and their absence in one derived by an error from the gene predictor.

\section{RESULTS}

Pathogenicity trials. Plants inoculated with strains Augusto2, CSV1, and I1.3 presented widely different symptoms (Fig. 1). At $22^{\circ} \mathrm{C}$ and $2 \mathrm{wpg}$, the symptoms of all strains were mixed between those associated with the two pathotypes identified by Niehaus et al. (2017); some plants showed elongation, whereas others were stunted. At $3 \mathrm{wpg}$, CSV1 induced stunting and withering, whereas I1.3 tended to induce more elongation and plants inoculated with Augusto2 could present both types of symptoms. Disease indexes are reported in Figure 2. Although all strains showed a similar virulence at $22^{\circ} \mathrm{C}$, Augusto2 and I1.3 were much more 
virulent at $31^{\circ} \mathrm{C}$ and nearly all of the plants died at $2 \mathrm{wpg}$, with the remaining plants showing extreme elongation.

In vitro trials. The three strains on YES Agar produced mycelia with a different color, dimension, and texture (Supplementary Fig. S1). CSV1 and I1.3 mycelia were characterized by a reverse redorange color not present in Augusto2. This color was also present in the front view of the CSV1 mycelia. In addition, growth speed was not uniform (Supplementary Fig. S2). CSV1 grew faster at the beginning of the trial, reaching a diameter of approximately $40 \mathrm{~mm}$ at 5 days after the inoculation. Afterward, Augusto 2 and I1.3 began to grow faster, reaching average diameters of 80 and $65 \mathrm{~mm}$ after 14 days of inoculation compared with $50 \mathrm{~mm}$ for CSV1.

Chemical analyses. The results of the in vivo quantification of GA 3 are presented in Figure 3 . At $22^{\circ} \mathrm{C}$ and $2 \mathrm{wpg}$, plants inoculated with Augusto 2 contained slightly more GA 3 than those inoculated with the other strains. However, 1 week later, the highest amount of GA3 was found in I1.3-inoculated plants. At $31^{\circ} \mathrm{C}$ and $2 \mathrm{wpg}$, the highest quantity of GA3 was found in plants inoculated with Augusto2 and I1.3, whereas plants affected by strain CSV1 had a GA3 quantity that was slightly but not significantly higher than the control plants. At 3 wpg, the quantity of GA3 in CSV1-inoculated plants decreased further, probably because many plants died. Fumonisins were not present in vivo at a detectable level in any of the plant samples.

GA3 and fumonisin production by the three strains was tested in vitro (Supplementary Table S4). CSV1 did not produce GA3 at detectable levels in vitro on YES Agar, but it was the highest producer on PDB (10,676.7 ppb). Fumonisins were produced in vitro by Augusto2 (181,052 ppb of FB1 on average) and much less by CSV1 (22 ppb of FB1), whereas I1.3 did not produce these mycotoxins in any situation.

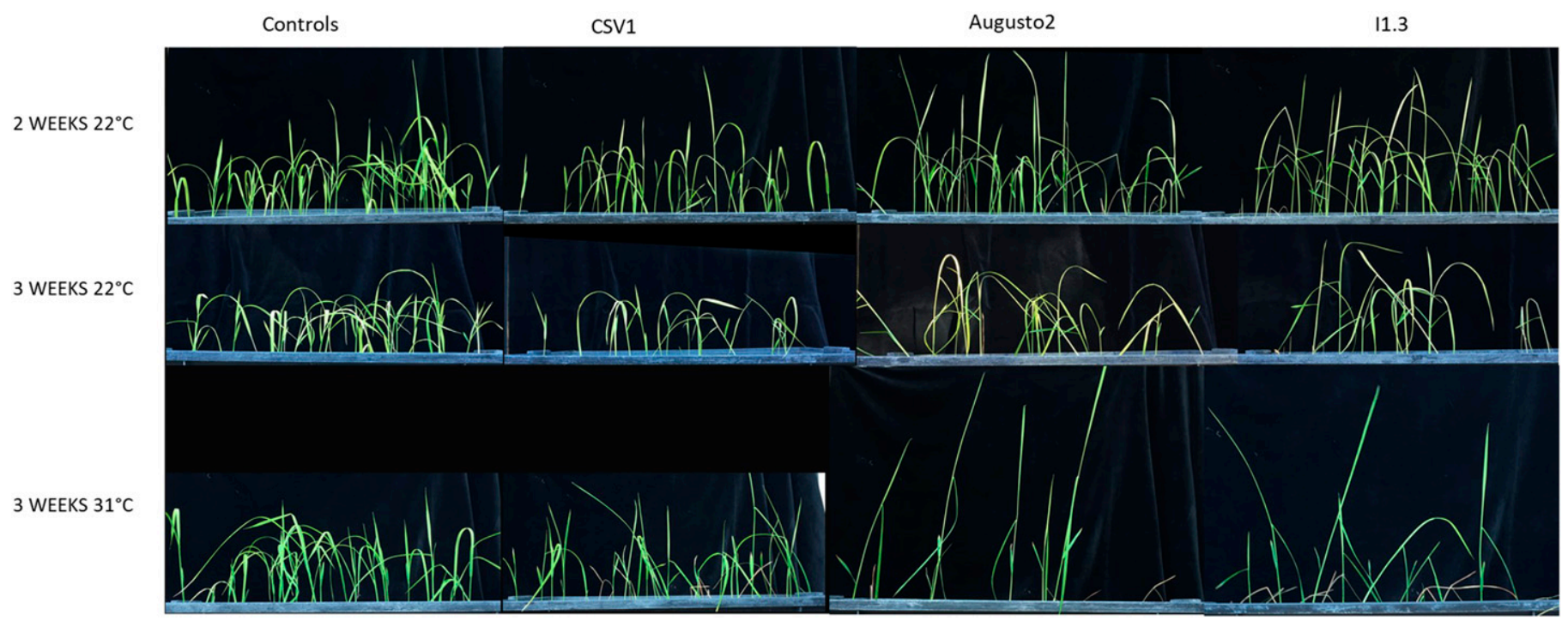

Fig. 1. Rice plants (cultivar Galileo) inoculated with Fusarium fujikuroi strains CSV1, Augusto2, or I1.3.

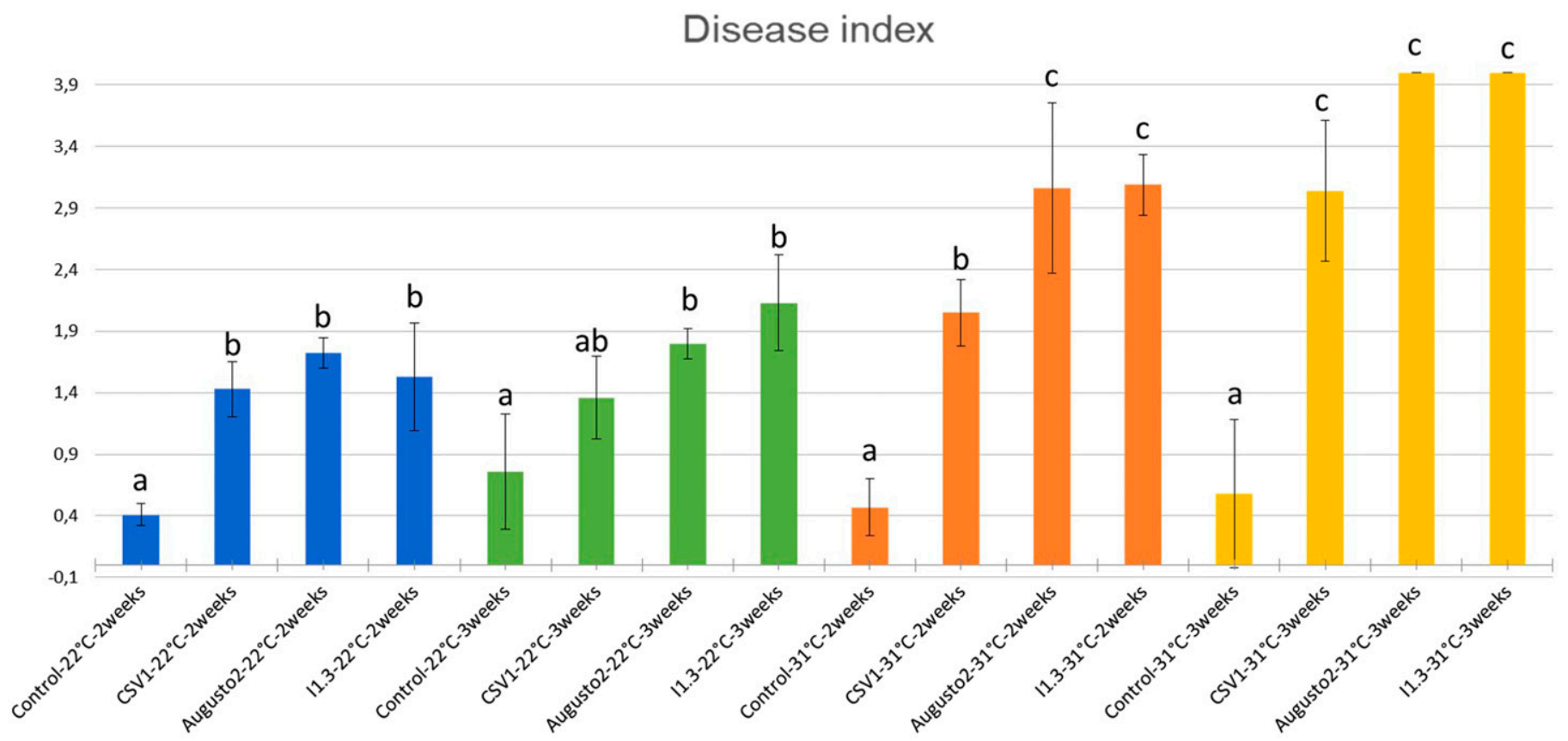

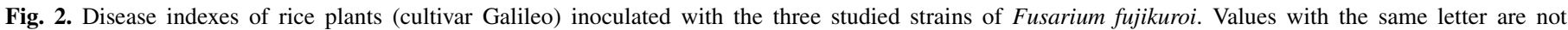
statistically different according to Duncan's test $(P<0.05)$. 
Real-time reverse transcription PCRs. The gene expression of cps/ks and gib20oxl at various time points is presented in Figure 4 . At $2 \mathrm{wpg}, \mathrm{cps} / \mathrm{ks}$ (a key gene of the fungal gibberellin gene cluster) was mainly expressed in I1.3-inoculated plants at both 22 and $31^{\circ} \mathrm{C}$. On the contrary, this gene was mostly expressed in strain CSV1 at $22^{\circ} \mathrm{C}$ and 3 wpg. In Augusto2, the expression level did not change significantly in the three examined conditions.

Regarding the gene gib20oxl (belonging to the plant gibberellin gene cluster), expression was higher in strain $\mathrm{I} 1.3$ at $22^{\circ} \mathrm{C}$ and 2 wpg, with CSV1 and Augusto2 showing similar expression. At $31^{\circ} \mathrm{C}$, the reverse transcription PCR results were similar in every strain, showing low expression; at $22^{\circ} \mathrm{C}$ and $3 \mathrm{wpg}$, CSV1 induced the highest level of expression, followed by I1.3 and Augusto2. Neither fum1 nor fum 21 expression was detected in plants at any time point, confirming the results obtained by the chemical analyses.

Sequencing, assembly, and bioinformatic analysis. The genome sequencing results are presented in Table 1. MiSeq Illumina sequencing produced 3.76, 3.9, and 2.12 million raw paired end reads for Augusto2, CSV1, and I1.3, respectively. For I1.3, 16.57 million mate pair reads were also obtained.

The estimated coverage, based on the $43.65-\mathrm{Mb}$ length of the reference genome of strain IMI 58289 (Wiemann et al. 2013), was

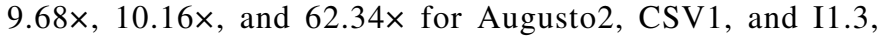
respectively. Starting from these data, the reference-guided approach with IMR/DENOM allowed us to reconstruct the 12 chromosomes of the three $F$. fujikuroi strains. Using MAKER, it was possible to predict 13,563, 13,578, and 13,690 proteins for Augusto2, CSV1, and I1.3, respectively. The assemblies and their annotations were deposited in GenBank as follows (with accession numbers in parentheses): I1.3 (CP023101 to CP023112), Augusto2 (CP023089 to CP023100), and CSV1 (CP023077 to CP023088).

The genes present in either Augusto2 or CSV1, but not in both, are listed in Supplementary Table S5.

SNP mining. Compared with the reference genome of F. fujikuroi strain IMI 58289, 178,594, 182,179, and 180,779 SNPs/indels were found in Augusto2, CSV1, and I1.3, respectively (Supplementary Data File S2). The distribution of these polymorphisms in the three strains is shown in Figure 5, and their position on the reference genome is presented in Figure 6 . The majority of the polymorphisms (>80\%; 148,623 SNPs/indels) were shared by the three strains. The differences between the analyzed strains and the reference strain were evaluated with SNPeff (Cingolani et al. 2012), and the results of this analysis are presented in Table 2. None of the strains presented a unique polymorphism in the gibberellin gene cluster, not even at the intergenic level (data not shown). With "unique polymorphism," a mutation not common to all three strains is meant. In the fumonisin gene clusters, on the other hand, there were a number of polymorphisms upstream and downstream of the genes, together with various unique missense polymorphisms. In particular, in the $I 1.3$ strain, there were four missense polymorphisms in transcription factor fum 21 and two in polyketide synthase fum1. One missense polymorphism in each of these two genes was also present in strains CSV1 and Augusto2.

Regarding the fusaric acid gene cluster, there were some intron and intergenic polymorphisms but no missense or nonsense polymorphisms. Unique missense and nonsense SNPs in the regulators were also searched (Supplementary Table S3), and one missense SNP in the sequence of the global regulator vea was identified in strains Augusto2 and I1.3. All of these polymorphisms were analyzed with PROVEAN Protein (Choi and Chan 2015), and two SNPs observed in strain I1.3 (one in polyketide synthase fum 1 and one in transcription factor fum 21 ) were predicted to have a deleterious effect on the function of their protein. CSV1 and Augusto2, despite their differences in phenotype, had most polymorphisms in common. Only 138 reference genes had a missense, nonsense, or frameshift polymorphism not common to both CSV1 and Augusto2. Of this subset, 34 genes had some GO terms related to pathogenicity, metabolism, or transcription regulation, and only eight had stop, frameshift, or missense mutations predicted to be deleterious by PROVEAN Protein (Supplementary Table S5). By mapping the reads on scaffold 005 of $F$. fujikuroi strain 005 (Genbank FMSL01000005.1), gene FFB14_06372 (encoding PKS51, a protein involved in causing stunting and withering in hosts) was not covered in reads in any of the strains, suggesting its absence in the analyzed genomes.

Structural variant analysis. The BreakDancer results are presented in Supplementary Data File S3. The analysis identified 107 deletions, 21 inversions, and three intrachromosomal translocations, putatively affecting the function of 66 genes in at least one of the strains.

Phylogenetic analysis. The analysis with OrthoFinder identified 14,699 orthogroups among the considered proteomes. In the resulting phylogenetic tree, F. fujikuroi strains Augusto2 and CSV1 seemed to be closer to each other than to I1.3, although it must be noted that the support values of the tree tended to be low (Supplementary Fig. S3).

Effector prediction and analysis. A list of 323 putative effectors was obtained by running EffectorP 1.0 and 2.0 on the F. fujikuroi secretome (Wiemann et al. 2013) and cross-referencing
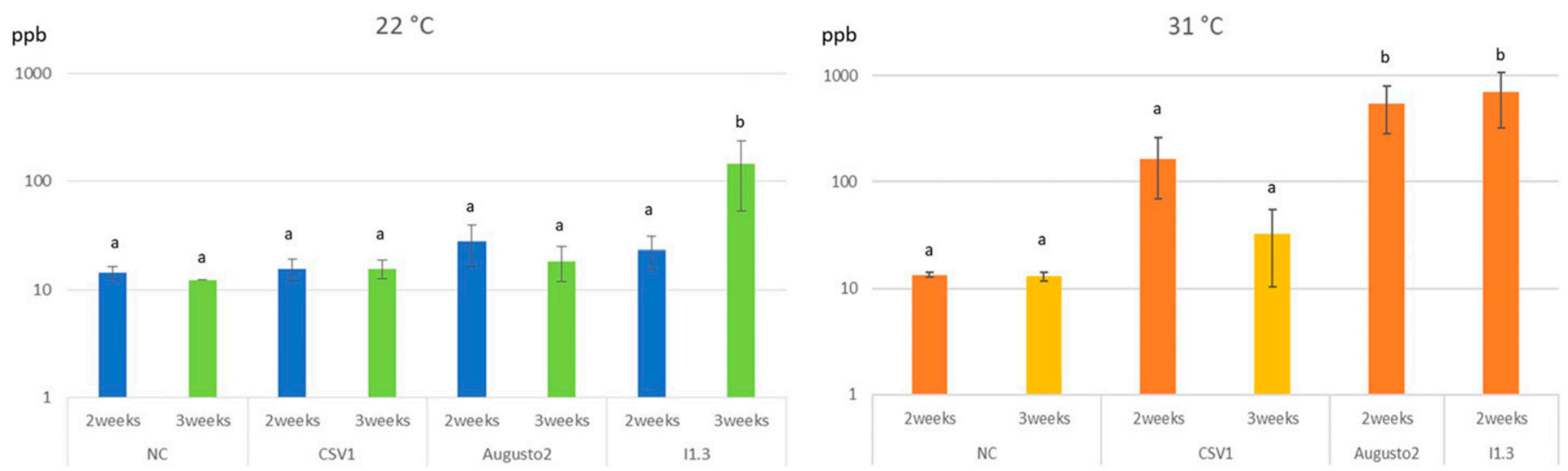

Fig. 3. GA3 quantity in rice plants (cultivar Galileo) inoculated with the three studied strains of Fusarium fujikuroi. Analysis was performed at 2 or 3 weeks postgermination at 22 and $31^{\circ} \mathrm{C}$. The error bars represent the standard deviation. Values followed by the same letter are not statistically different by Duncan's multiple range test $(P<0.05)$. This test was executed in an independent manner for the samples at $22^{\circ} \mathrm{C}$ and those at $31^{\circ} \mathrm{C}$. 
the results (Sperschneider et al. 2016). Two of the identified genes had missense polymorphisms present in CSV1 but not in Augusto2: FFUJ_01956 and FFUJ_11601. Analysis with PROVEAN Protein, however, predicted that these two polymorphisms did not have an effect on the protein function.

\section{DISCUSSION}

Temperature effect. This work investigated the effect of temperature in the rice- $F$. fujikuroi pathosystem: three newly sequenced $F$. fujikuroi strains induced different symptoms in rice

A

$c p s / k s$

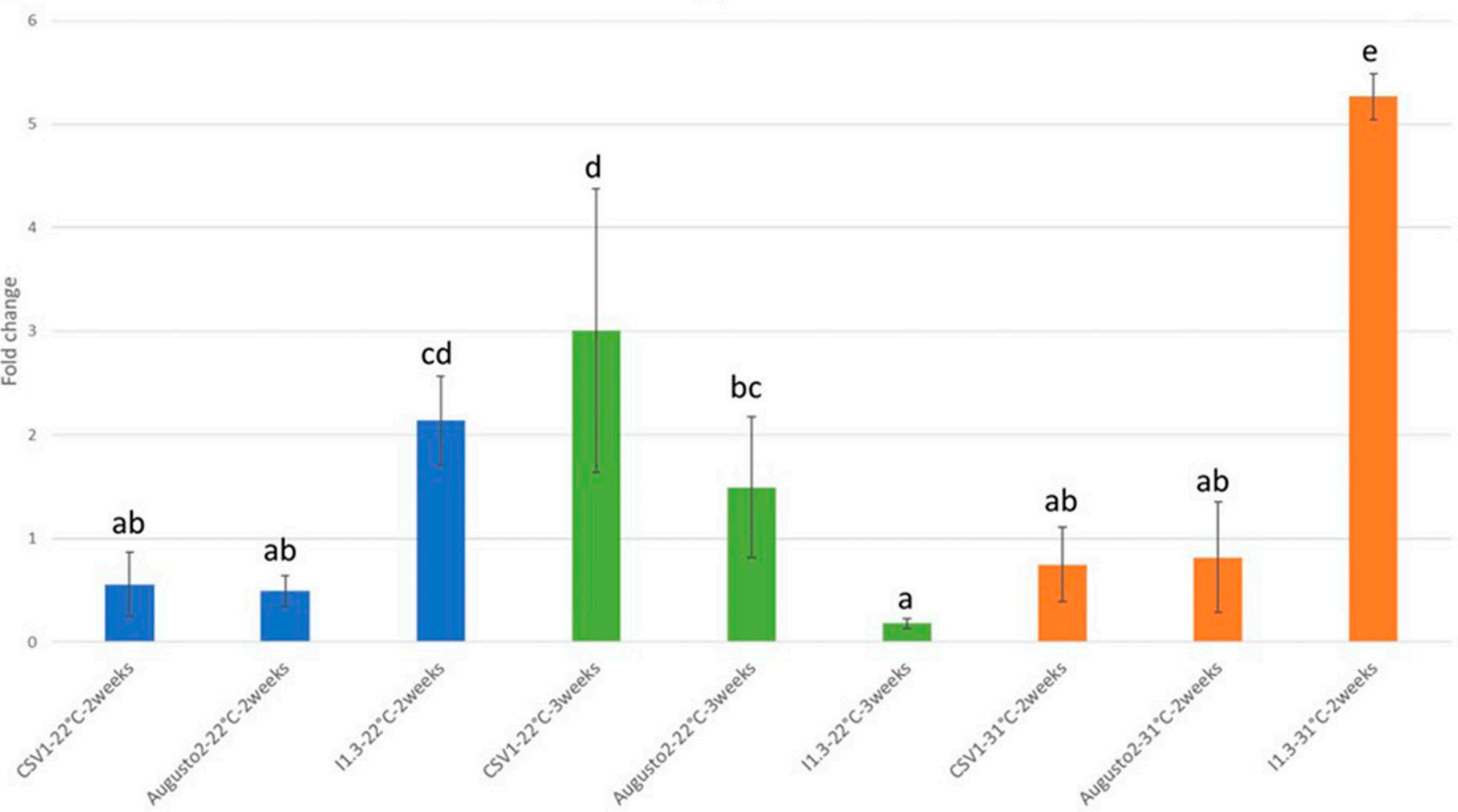

\section{B}

Gibberellin 20 oxidase 1

120

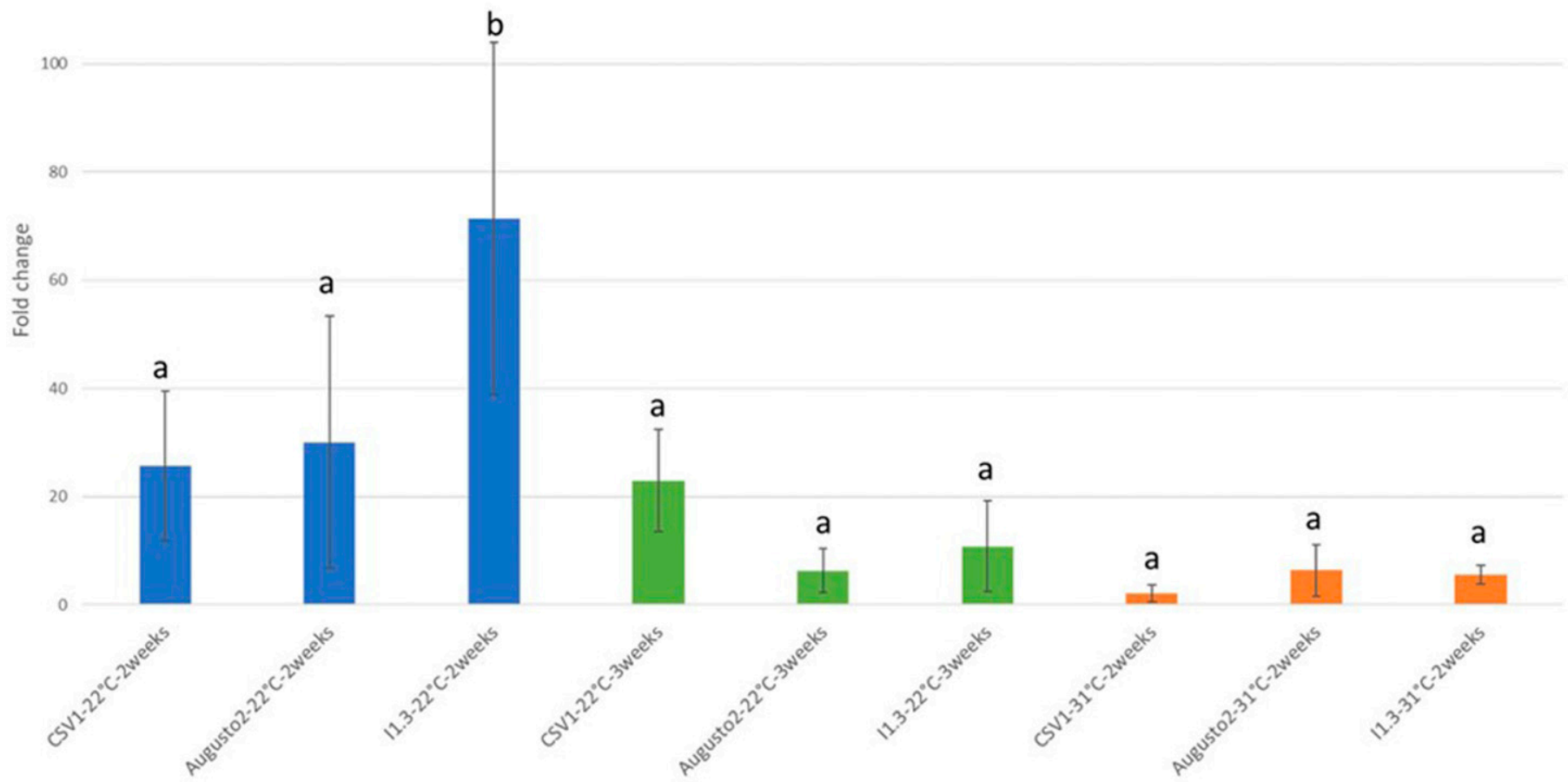

Fig. 4. Gene expression of $\mathbf{A}, c p s / k s$, a gene of the Fusarium fujikuroi gibberellin cluster, and $\mathbf{B}$, Gibberellin 20 oxidase 1, a gene of the rice gibberellin cluster. Data obtained by reverse transcription real-time PCR. The error bar is the standard deviation. Values followed by the same letter are not statistically different by Duncan's multiple range test $(P<0.05)$. 
depending on the temperature. Pathogenicity trials were conducted with three strains of different virulence; in every case, the pathogen was much more virulent at $31^{\circ} \mathrm{C}$ than at $22^{\circ} \mathrm{C}$. In fact, strains I1.3 and Augusto 2 were so virulent at $31^{\circ} \mathrm{C}$ that most of the plants were dead after 2 wpg.

Niehaus et al. (2017) showed that there are at least two pathotypes of $F$. fujikuroi, one that is associated with bakanae-like symptoms and gibberellin production and another that induces withering and stunting. The pathotypes are thought to be diverse from a phylogenetic, symptomatic, and metabolomic point of view. However, in the current study, strains phylogenetically close to each other were capable of inducing both types of symptoms. At $22^{\circ} \mathrm{C}$ and $2 \mathrm{wpg}$, the symptoms of all strains were mixed, with some plants showing elongation and some stunting (Fig. 1). However, at this time point, I1.3 showed high expression of both $\mathrm{cps} / \mathrm{ks}$ and gib20oxl (Fig. 4), belonging to the fungal and plant gibberellin gene clusters, respectively, and this induced "bakanae-like" symptoms 1 week later in all plants. Conversely, CSV1 and Augusto2 did not strongly express the gibberellin gene clusters; therefore, the induced symptom was mostly dwarfism, with no elongation in CSV1 and slight elongation in Augusto2 (Fig. 1). This was corroborated by the HPLC-MS analysis: plants inoculated with strain I1.3 contained a higher concentration of GA3 at $3 \mathrm{wpg}$, although the quantities were similar for every strain 1 week earlier (Fig. 3). On the other hand, the surviving plants inoculated with Augusto 2 and I1.3 showed elongation at $31^{\circ} \mathrm{C}$ (Fig. 1) and they had a very high content in GA3 (Fig. 3), whereas CSV1 mostly induced stunting and contained less GA3. In addition, the expression of $c p s /$ $k s$ and gib20ox 1 was low in CSV1, and the GA3 level was even less 1 week later. The very low number of surviving plants did not permit us to perform analysis at $31^{\circ} \mathrm{C}$ and $3 \mathrm{wpg}$ for Augusto 2 and I1.3, but they both showed low expression of gib20oxl at $2 \mathrm{wpg}$, although significant expression of $c p s / k s$ was measured in I1.3. Even at 2 wpg, most of the plants were dead, so the significantly greater expression of $\mathrm{cps} / \mathrm{ks}$ in I1.3 at $2 \mathrm{wpg}$ was attributable to the survival of few plants that showed a high expression level.

In conclusion, it seems that despite their proximity from a phylogenetical point of view (Fig. 5), I1.3 induces a "bakanaelike" phenotype at all temperatures and CSV1 is characterized by low GA3 production and stunting, whereas Augusto2 is actually capable of changing the induced symptoms depending on the temperature, being closer to $\mathrm{I} 1.3$ at $31^{\circ} \mathrm{C}$ and a mix of both phenotypes at $22^{\circ} \mathrm{C}$. The gene encoding PKS51, associated with the $F$. fujikuroi pathotype causing stunting and withering, was not present in the three examined strains.

Fumonisin production. Fumonisins are mycotoxins that produce a vast array of effects on animals, including nephrotoxicity and hepatotoxicity (Bolger et al. 2001) as well as neurotoxicity and cardiotoxicity (Scott 2012), when consumed. In this study, fumonisins or fumonisin transcripts were not detected in vivo with HPLC-MS or real-time PCRs, but this was expected given the fact that this pathogen produces minimal amounts of these metabolites (Wiemann et al. 2013). However, fumonisins were detected in vitro for strains Augusto2 and CSV1. I1.3 did not produce fumonisins at a detectable level in vivo or in vitro, likely as an effect of the

TABLE 1. Data regarding the genome reference-guided assembly and annotation of strains Augusto2, CSV1, and I1.3 of Fusarium fujikuroi

\begin{tabular}{lccc}
\hline Characteristic & Augusto2 & CSV1 & I1.3 \\
\hline Genome size $(\mathrm{Mb})$ & $\sim 43.7$ & $\sim 43.7$ & $\sim 45.6$ \\
Sequencing coverage & $9.7 \times$ & $10.2 \times$ & $62.3 \times$ \\
Contigs $(n)$ & 12 & 12 & 12 \\
Large contigs $(>100 \mathrm{~Kb})(n)$ & 12 & 12 & 12 \\
N50 (base pairs) & $4,218,434$ & $4,212,448$ & $4,426,414$ \\
GC content $(\%)$ & 47.49 & 47.51 & 47.2 \\
Genes $(n)$ & 13,563 & 13,578 & 13,690 \\
Annotated genes $(n)$ & 10,073 & 10,080 & 9,838 \\
\hline
\end{tabular}

putatively important polymorphisms that this strain has in transcription factor fum 21 and polyketide synthase fum1, since both genes are essential for the correct functioning of the gene cluster (Alexander et al. 2009).

Cruz et al. (2013) found no relationship between pathogenicity and the ability to produce fumonisins in F. fujikuroi, whereas Niehaus et al. (2017) observed that the deletion of the fumonisin PKS caused a reduction in virulence but only in stunting-inducing strains. Our data correlate well with these studies: none of our strains produced fumonisins in a detectable quantity in vivo; although this has likely a negligible effect on the virulence of I1.3 and Augusto2, it may impact the virulence of CSV1, which induced stunting at both of the tested temperatures and presented a lower virulence than the other two isolates.

In the work of Matic et al. (2013), the fumonisin synthesis of the same three strains was analyzed, with similar results: Augusto2 produced by far the highest quantity of these mycotoxins, followed by CSV1. Interestingly, in the conditions tested in that work, strain I1.3 was able to produce a small amount of fumonisin B1.

Different phenotypes, similar genomes. The three sequenced $F$. fujikuroi strains were isolated from the same geographic area, but their phenotype was very different. CSV1 and Augusto2 are particularly close from an evolutionary point of view (Supplementary Fig. S3), with only 21,887 SNPs between them, but they differ in virulence, reaction to temperature, induced symptoms, colony morphology and color, growth speed, fumonisin and gibberellin production. Given the low sequencing coverage used, the number of SNPs was likely underestimated, but the high percentage of shared polymorphisms (93\% of the total for CSV1 and $95 \%$ for Augusto2) is further proof of the low evolutionary distance between the two strains.

The most common genes involved in pathogenesis and gibberellin production were checked for polymorphisms, but no SNPs that could explain these variations were found. Even if Augusto2 and I1.3 had a missense SNP in vea, a regulator of secondary metabolism associated with fumonisin and fusarin production, there is currently no evidence linking fusarins to the

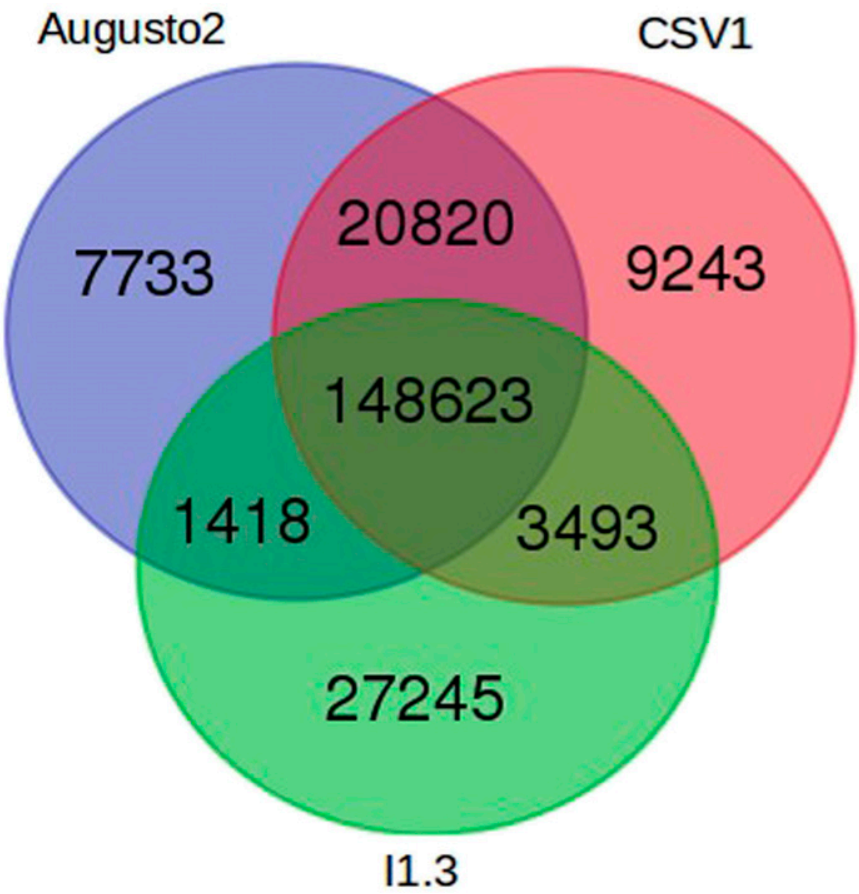

Fig. 5. Venn diagram showing the distribution of polymorphisms among the Fusarium fujikuroi strains Augusto2, CSV1, and I1.3. The genome of strain IMI 58289 was used as the reference in the single nucleotide polymorphism calling. The image was obtained with the software available at http:// bioinformatics.psb.ugent.be/webtools/Venn/. 
development of the disease. In addition, fumonisin production is believed to have no relationship with pathogenicity of elongationinducing F. fujikuroi (Cruz et al. 2013; Niehaus et al. 2017), and none of the considered strains produced fumonisins at a detectable level in vivo. Two putative effectors presented missense polymorphisms in CSV1 and not in the other strains, but a prediction analysis with PROVEAN Protein showed that it is unlikely that these differences would affect protein function.

The differences between the genomes of Augusto 2 and CSV1 were further investigated by checking missense, frameshift, or nonsense SNPs present in either CSV1 or Augusto2, but not both. The genes presenting these polymorphisms were filtered by checking for GO terms related to metabolism, pathogenicity, or gene regulation, and the missense SNPs were evaluated with PROVEAN Protein, discarding those with a putative neutral effect. The remaining genes are listed in Supplementary Table S5, which also contains the genes putatively affected by a structural variant in either Augusto2 or CSV1, but not in both. Another source of phenotype variation could be the absence or presence of certain genes in the genomes, although only 14 genes were present in either Augusto2 or CSV1, but not in both (Supplementary Table S5).

The genes with predicted function-affecting polymorphisms do not seem to be directly correlated with the observed differences in

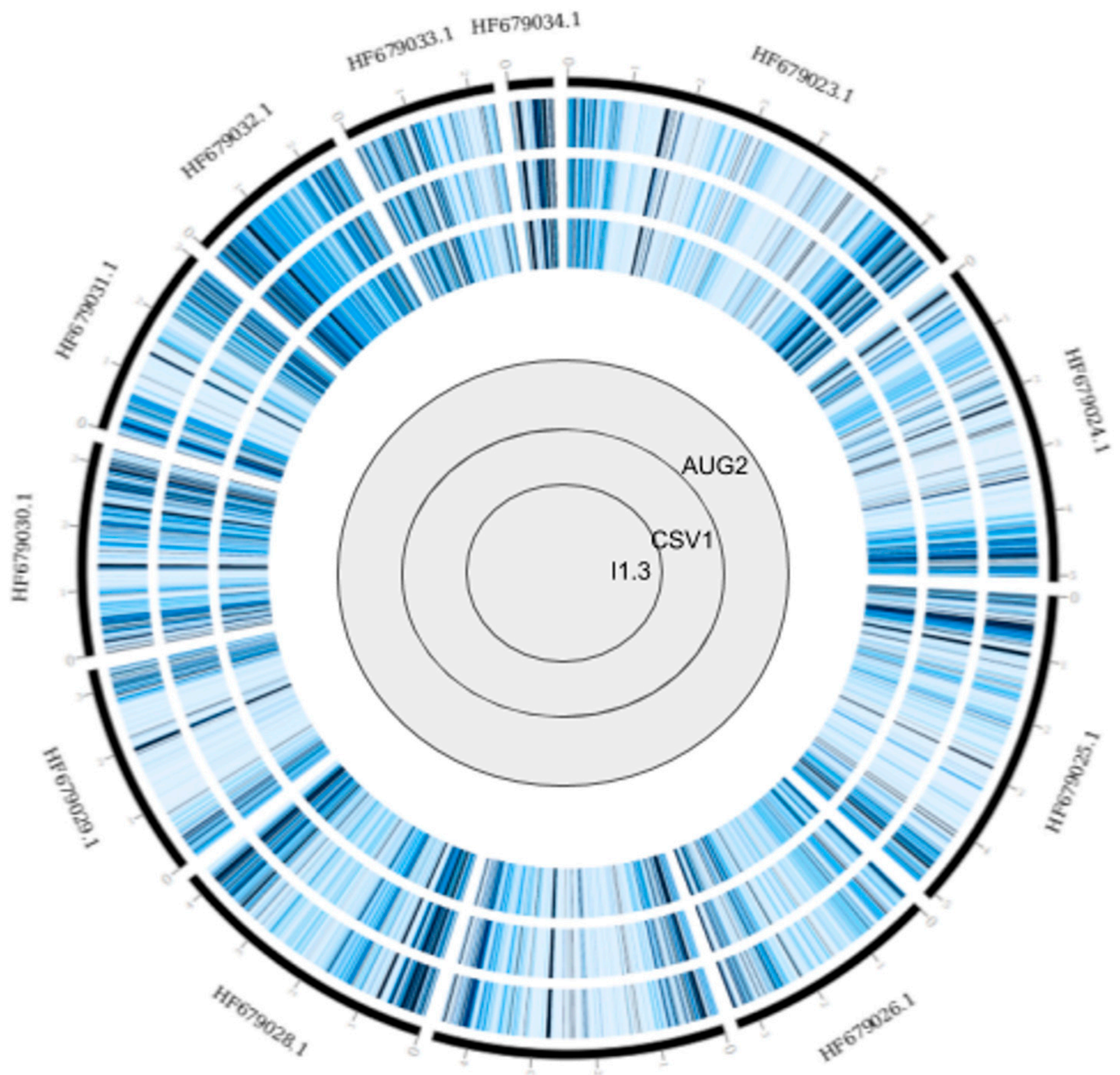

\section{HF679027.1}

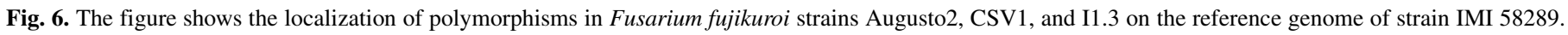

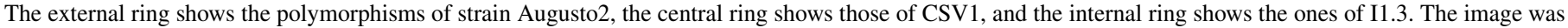
obtained with CircosVCF (Drori et al. 2017). 
the phenotype, nor do the genes present in only one of the genomes. However, protein CCT62922.1, a pisatin demethylase, was putatively affected by an inversion in CSV1, and this class of proteins is known to be a factor of virulence in both $F$. oxysporum and F. solani (Rocha et al. 2016; Wasmann and VanEtten 1996). Conversely, CCT63174.1, an endo polygalacturonase (a virulence factor in F. graminearum; Paccanaro et al. 2017), was removed by a deletion in Augusto2 and I1.3 but not in CSV1. Another protein putatively not functioning in Augusto2 was CCT73390.1, an integral membrane protein, and some proteins of this class are factors of virulence for plant pathogens, such as integral membrane protein PTH11, which is required for pathogenicity and appressorium formation in Magnaporthe grisea and exhibits hostpreferential expression in F. graminearum (DeZwaan et al. 1999; Harris et al. 2016). Finally, CCT74990.1, related to a fructosyl amino acid oxidase, was predicted to be affected by an inversion in CSV1, but this protein was proven to be dispensable for development and growth in Aspergillus nidulans, whose null mutant for this gene grew normally and developed as many conidia and sexual structures as the wild type (Jeong et al. 2002). Besides these proteins, a number of the genes presented in Supplementary Table S5 are currently uncharacterized, and their activity could contribute to the differences observed between Augusto2 and CSV1.

Conclusions. This study presents a comparative genomics analysis of three F. fujikuroi strains isolated in Northern Italy, the largest European production area of rice. The strains showed a remarkable difference in phenotype, despite being very close from an evolutionary point of view, suggesting that a few key mutations in a small number of genes can dramatically alter the phenotype induced by the pathogen. A few candidate genes that may explain these phenotypic differences were identified.

$F$. fujikuroi was recently divided into two phylogenetically separated pathotypes (Niehaus et al. 2017), which induce either bakanae symptoms or stunting and withering, respectively. However, in this study, it has been observed that minimal genetic differences can induce symptom modifications and some strains may be able to induce both types of phenotypes, depending on environmental factors such as temperature.

Finally, it was observed that the $F$. fujikuroi strains considered became much more virulent at higher temperatures. This observation could be linked to the effect of occurring climatic changes. The rise of average temperatures in spring may affect rice production not only with increasing losses induced by abiotic stresses but also with the average increase of virulence of $F$. fujikuroi. Although the danger posed to rice by climate change favoring abiotic stresses is known (Mohammed and Tarpley 2009) and efforts are underway to obtain climate-resilient cultivars (Sreenivasulu et al. 2015), there is

TABLE 2. Number and putative effect of polymorphisms detected in strains CSV1, Augusto2, and I1.3 of Fusarium fujikuro i ${ }^{\mathrm{a}}$

\begin{tabular}{lrrr}
\hline Characteristic & CSV1 & Augusto2 & \multicolumn{1}{c}{ I1.3 } \\
\hline Polymorphisms $(n)$ & 182,179 & 178,594 & 180,779 \\
$\quad$ Single nucleotide polymorphisms & 176,34 & 172,722 & 174,933 \\
Insertions & 3,061 & 3,08 & 3,082 \\
$\quad$ Deletions & 2,778 & 2,778 & 2,764 \\
$\quad$ Variant rate (bases) & $1 / 241$ & $1 / 245$ & $1 / 242$ \\
Predicted polymorphism effect $(n)$ & & & \\
$\quad$ Silent & 41,476 & 41,457 & 41,375 \\
$\quad$ Missense & 27,404 & 27,385 & 27,356 \\
$\quad$ Nonsense & 376 & 373 & 373 \\
Polymorphism impact $(n)$ & & & \\
High & 973 & 973 & 949 \\
Moderate & 27,589 & 27,565 & 27,551 \\
$\quad$ Low & 43,318 & 43,301 & 43,228 \\
Negligible & 714,739 & 708,481 & 712,012 \\
\hline
\end{tabular}

a The reference used for the single nucleotide polymorphism calling was the genome of $F$. fujikuroi strain IMI 58289. little knowledge of the impact of increased temperatures on the interactions between rice and fungal pathogens.

\section{ACKNOWLEDGMENTS}

We thank Ilenia Siciliano for performing part of the chemical analyses and Houda Banani for measuring the in vitro growth of the microorganisms.

\section{LITERATURE CITED}

Alexander, N. J., Proctor, R. H., and McCormick, S. P. 2009. Genes, gene clusters, and biosynthesis of trichothecenes and fumonisins in Fusarium. Toxin Rev. 28:198-215.

Amatulli, M. T., Spadaro, D., Gullino, M. L., and Garibaldi, A. 2010. Molecular identification of Fusarium spp. associated with bakanae disease of rice in Italy and assessment of their pathogenicity. Plant Pathol. 59:839-844.

Amoah, B. K., Rezanoor, H. N., Nicholson, P., and Macdonald, M. V. 1995. Variation in the Fusarium section Liseola: Pathogenicity and genetic studies of isolates of Fusarium moniliforme Sheldon from different hosts in Ghana. Plant Pathol. 44:563-572.

Bacon, C. W., Porter, J. K., Norred, W. P., and Leslie, J. F. 1996. Production of fusaric acid by Fusarium species. Appl. Environ. Microbiol. 62:4039-4043.

Bagga, P. S., and Kumar, V. 2000. Resistance to bakanae or foot-rot disease in basmati rice. Indian Phytopathol. 53:321-322.

Balan, J., Fuska, J., Kuhr, I., and Kuhrova, V. 1970. Bikaverin, an antibiotic from Gibberella fujikuroi, effective against Leishmania brasiliensis. Folia Microbiol. (Praha) 15:479-484.

Bankevich, A., Nurk, S., Antipov, D., Gurevich, A. A., Dvorkin, M., Kulikov, A. S., Lesin, V. M., Nikolenko, S. I., Pham, S., Prjibelski, A. D., and Pyshkin, A. V. 2012. SPAdes: A new genome assembly algorithm and its applications to single-cell sequencing. J. Comput. Biol. 19:455-477.

Barrero, A. F., Sánchez, J. F., Oltra, J. E., Tamayo, N., Cerdá-Olmedo, E., Candau, R., and Avalos, J. 1991. Fusarin C and 8Z-fusarin C from Gibberella fujikuroi. Phytochemistry 30:2259-2263.

Bashyal, B. M., Rawat, K., Sharma, S., Kulshreshtha, D., Gopala Krishnan, S., Singh, A. K., Dubey, H., Solanke, A. U., Sharma, T. R., and Aggarwal, R. 2017. Whole genome sequencing of Fusarium fujikuroi provides insight into the role of secretory proteins and cell wall degrading enzymes in causing bakanae disease of rice. Front. Plant Sci. 8:2013.

Bolger, M., Coker, R. D., Dinovi, M., Gaylor, D., Gelderblom, M. O., Paster, N., Riley, R. T., Shephard, G., and Speijers, J. A. 2001. Fumonisins. Pages 103-297 in: Safety Evaluation of Certain Mycotoxins in Food, No. 47. Food Additives Series. Food and Agriculture Organization of the United Nations, Geneva, Switzerland.

Cantarel, B. L., Korf, I., Robb, S. M., Parra, G., Ross, E., Moore, B., Holt, C., Alvarado, A. S., and Yandell, M. 2008. MAKER: An easy-to-use annotation pipeline designed for emerging model organism genomes. Genome Res. 18: 188-196.

Carter, L. L. A., Leslie, J. F., and Webster, R. K. 2008. Population structure of Fusarium fujikuroi from California rice and water grass. Phytopathology 98:992-998.

Chiara, M., Fanelli, F., Mule, G., Logrieco, A. F., Pesole, G., Leslie, J. F., Horner, D. S., and Toomajian, C. 2015. Genome sequencing of multiple isolates highlights subtelomeric genomic diversity within Fusarium fujikuroi. Genome Biol. Evol. 7:3062-3069.

Choi, Y., and Chan, A. P. 2015. PROVEAN web server: A tool to predict the functional effect of amino acid substitutions and indels. Bioinformatics 31 : 2745-2747.

Chu, F. S., and Li, G. Y. 1994. Simultaneous occurrence of fumonisin B1 and other mycotoxins in moldy corn collected from the People's Republic of China in regions with high incidences of esophageal cancer. Appl. Environ. Microbiol. 60:847-852.

Cingolani, P., Platts, A., Wang, L. L., Coon, M., Nguyen, T., Wang, L., Land, S. J., Lu, X., and Ruden, D. M. 2012. A program for annotating and predicting the effects of single nucleotide polymorphisms, SnpEff. Fly (Austin) 6:80-92.

Creppy, E. E. 2002. Update of survey, regulation and toxic effects of mycotoxins in Europe. Toxicol. Lett. 127:19-28.

Cruz, A., Marín, P., González-Jaén, M. T., Aguilar, K. G. I., and Cumagun, C. J. R. 2013. Phylogenetic analysis, fumonisin production and pathogenicity of Fusarium fujikuroi strains isolated from rice in the Philippines. J. Sci. Food Agric. 93:3032-3039.

Desjardins, A. E., Plattner, R. D., and Gordon, T. R. 2000. Gibberella fujikuroi mating population A and Fusarium subglutinans from teosinte species and maize from Mexico and Central America. Mycol. Res. 104:865-872.

Desjardins, A. E., Plattner, R. D., and Nelson, P. E. 1997. Production of fumonisin B (inf1) and moniliformin by Gibberella fujikuroi from rice from various geographic areas. Appl. Environ. Microbiol. 63:1838-1842. 
DeZwaan, T. M., Carroll, A. M., Valent, B., and Sweigard, J. A. 1999. Magnaporthe grisea pth11p is a novel plasma membrane protein that mediates appressorium differentiation in response to inductive substrate cues. Plant Cell 11:2013-2030.

Drori, E., Levy, D., Smirin-Yosef, P., Rahimi, O., and Salmon-Divon, M. 2017. CircosVCF: Circos visualization of whole-genome sequence variations stored in VCF files. Bioinformatics 33:1392-1393.

Emms, D., and Kelly, S. 2018. STAG: Species tree inference from all genes. bioRxiv 267914.

Emms, D. M., and Kelly, S. 2015. OrthoFinder: Solving fundamental biases in whole genome comparisons dramatically improves orthogroup inference accuracy. Genome Biol. 16:157.

Fan, X., Abbott, T. E., Larson, D., and Chen, K. 2014. BreakDancer: Identification of genomic structural variation from paired-end read mapping. Curr. Protoc. Bioinformatics 45:15-16.

Fiyaz, R. A., Yadav, A. K., Krishnan, S. G., Ellur, R. K., Bashyal, B. M., Grover, N., Bhowmick, P. K., Nagarajan, M., Vinod, K. K., Singh, N. K., and Prabhu, K. V. 2016. Mapping quantitative trait loci responsible for resistance to bakanae disease in rice. Rice (N. Y.) 9:45

Gupta, A. K., Solanki, I. S., Bashyal, B. M., Singh, Y., and Srivastava, K. 2015. Bakanae of rice-an emerging disease in Asia. J. Anim. Plant Sci. 25:1499-1514.

Harris, L. J., Balcerzak, M., Johnston, A., Schneiderman, D., and Ouellet, T. 2016. Host-preferential Fusarium graminearum gene expression during infection of wheat, barley, and maize. Fungal Biol-UK. 120:111-123.

Janevska, S., and Tudzynski, B. 2018. Secondary metabolism in Fusarium fujikuroi: Strategies to unravel the function of biosynthetic pathways. Appl. Microbiol. Biotechnol. 102:615-630.

Jeong, H., Lee, S., Choi, G. J., Lee, T., and Yun, S. H. 2013. Draft genome sequence of Fusarium fujikuroi B14, the causal agent of the bakanae disease of rice. Genome Announc. 1:e00035-13.

Jeong, H. Y., Song, M., Back, J., Han, D. M., Wu, X., Monnier, V., Jahng, K. Y., and Chae, K. S. 2002. The veA gene is necessary for the inducible expression by fructosyl amines of the Aspergillus nidulans faoA gene encoding fructosyl amino acid oxidase (amadoriase, EC 1.5.3). Arch. Microbiol. 178:344-350.

Ji, H., Kim, T. H., Lee, G. S., Kang, H. J., Lee, S. B., Suh, S. C., Kim, S. L., Choi, I., Baek, J., and Kim, K. H. 2018. Mapping of a major quantitative trait locus for bakanae disease resistance in rice by genome resequencing. Mol. Genet. Genomics 293:579-586.

Karov, I., Mitrev, S., and Arsov, E. 2009. Giberella fujikuroi (Wollenweber) the new parasitical fungus on rice in the Republic of Macedonia. Proc. Nat. Sci. Matica Srpska Novi Sad 116:175-182.

Kim, S. Y., Park, D. S., Lee, I. J., Park, Y. G., Seo, J. H., Bae, H. K., Hwang, C. D., and Ko, J. M. 2018. Disease incidence, growth, and physiological characterization of rice cultivars with different susceptibility to bakanae disease. Philipp. J. Crop Sci. 43:38-46.

Kumar, S., Tamura, K., and Nei, M. 1994. MEGA: Molecular evolutionary genetics analysis software for microcomputers. Bioinformatics 10:189-191.

Lechner, M., Findeiß, S., Steiner, L., Marz, M., Stadler, P. F., and Prohaska, S. J. 2011. Proteinortho: Detection of (Co-) orthologs in large-scale analysis. BMC Bioinformatics 12:124.

Li, H., and Durbin, R. 2009. Fast and accurate short read alignment with Burrows-Wheeler transform. Bioinformatics 25:1754-1760.

Manosalva, P. M., Davidson, R. M., Liu, B., Zhu, X., Hulbert, S. H., Leung, H., and Leach, J. E. 2009. A germin-like protein gene family functions as a complex quantitative trait locus conferring broad-spectrum disease resistance in rice. Plant Physiol. 149:286-296.

Matić, S., Bagnaresi, P., Biselli, C., Carneiro, G. A., Siciliano, I., Valé, G., Gullino, M. L., and Spadaro, D. 2016. Comparative transcriptome profiling of resistant and susceptible rice genotypes in response to the seedborne pathogen Fusarium fujikuroi. BMC Genomics 17:608.

Matić, S., Gullino, M. L., and Spadaro, D. 2017. The puzzle of bakanae disease through interactions between Fusarium fujikuroi and rice. Front. Biosci. Elite 9:333-344.

Matić, S., Spadaro, D., Prelle, A., Gullino, M. L., and Garibaldi, A. 2013. Light affects fumonisin production in strains of Fusarium fujikuroi, Fusarium proliferatum, and Fusarium verticillioides isolated from rice. Int. J. Food Microbiol. 166:515-523.

Milne, I., Stephen, G., Bayer, M., Cock, P. J., Pritchard, L., Cardle, L., Shaw, P. D., and Marshall, D. 2013. Using tablet for visual exploration of secondgeneration sequencing data. Brief. Bioinform. 14:193-202.

Mohammed, A. R., and Tarpley, L. 2009. Impact of high nighttime temperature on respiration, membrane stability, antioxidant capacity, and yield of rice plants. Crop Sci. 49:313-322

Niehaus, E. M., Kim, H. K., Münsterkötter, M., Janevska, S., Arndt, B., Kalinina, S. A., Houterman, P. M., Ahn, I. P., Alberti, I., Tonti, S., and Kim, D. W. 2017. Comparative genomics of geographically distant Fusarium fujikuroi isolates revealed two distinct pathotypes correlating with secondary metabolite profiles. PLoS Pathog 13:e1006670.

Niehaus, E. M., Rindermann, L., Janevska, S., Münsterkötter, M., Güldener, U., and Tudzynski, B. 2018. Analysis of the global regulator Lae1 uncovers a connection between Lae1 and the histone acetyltransferase HAT1 in Fusarium fujikuroi. Appl. Microbiol. Biotechnol. 102:279-295.

Paccanaro, M. C., Sella, L., Castiglioni, C., Giacomello, F., Martínez-Rocha, A. L., D'Ovidio, R., Schäfer, W., and Favaron, F. 2017. Synergistic effect of different plant cell wall-degrading enzymes is important for virulence of Fusarium graminearum. Mol. Plant-Microbe Interact. 30:886-895.

Pfannmüller, A., Leufken, J., Studt, L., Michielse, C. B., Sieber, C. M., Güldener, U., Hawat, S., Hippler, M., Fufezan, C., and Tudzynski, B. 2017. Comparative transcriptome and proteome analysis reveals a global impact of the nitrogen regulators AreA and AreB on secondary metabolism in Fusarium fujikuroi. PLoS One 12:e0176194.

Radwan, O., Gunasekera, T. S., and Ruiz, O. N. 2018. Draft genome sequence of Fusarium fujikuroi, a fungus adapted to the fuel environment. Genome Announc. 6:e01499-17

Rocha, L. O., Laurence, M. H., Ludowici, V. A., Puno, V. I., Lim, C. C., Tesoriero, L. A., Summerell, B. A., and Liew, E. C. Y. 2016. Putative effector genes detected in Fusarium oxysporum from natural ecosystems of Australia. Plant Pathol. 65:914-929.

Saremi, H., Ammarellou, A., Marefat, A., and Okhovvat, S. M. 2008. Binam a rice cultivar, resistant for root rot disease on rice caused by Fusarium moniliforme in Northwest, Iran. Int. J. Bot. 4:383-389.

Saremi, H., and Farrokhi, F. 2004. Study on bakanae disease of rice and evaluation of cultivars in Gilan and Zanjan provinces, Iran. Proc. Fourth Inter. Iran Russia Conf. 358-364.

Scott, P. M. 2012. Recent research on fumonisins: A review. Food Addit. Contam. A 29:242-248.

Siciliano, I., Amaral Carneiro, A., Spadaro, D., Garibaldi, A., and Gullino, M. L. 2015. Jasmonic acid, abscisic acid and salicylic acid are involved in the phytoalexin responses of rice to Fusarium fujikuroi, a high gibberellin producer pathogen. J. Agric. Food Chem. 63:8134-8142.

Sperschneider, J., Gardiner, D. M., Dodds, P. N., Tini, F., Covarelli, L., Singh, K. B., Manners, J. M., and Taylor, J. M. 2016. EFFECTOR P: Predicting fungal effector proteins from secretomes using machine learning. New Phytol. 210:743-761.

Sreenivasulu, N., Butardo, V. M., Misra, G., Cuevas, R. P., Anacleto, R., and Kishor, P. B. K. 2015. Designing climate-resilient rice with ideal grain quality suited for high-temperature stress. J. Exp. Bot. 66:1737-1748.

Stanke, M., and Waack, S. 2003. Gene prediction with a hidden Markov model and a new intron submodel. Bioinformatics 19:ii215-ii225.

Stępień, Ł., Koczyk, G., and Waśkiewicz, A. 2011. FUM cluster divergence in fumonisins-producing Fusarium species. Fungal Biol-UK 115:112-123.

Studt, L., Wiemann, P., Kleigrewe, K., Humpf, H. U., and Tudzynski, B. 2012. Biosynthesis of fusarubins accounts for pigmentation of Fusarium fujikuroi perithecia. Appl. Environ. Microbiol. 78:4468-4480.

Sydenham, E. W., Thiel, P. G., Marasas, W. F. O., Shephard, G. S., van Schalkwyk, D. J., and Koch, K. R. 1990. Natural occurrence of some Fusarium mycotoxins in corn from low and high esophageal cancer prevalence areas of the Transkei, southern Africa. J. Agric. Food Chem. 38: 1900-1903.

Tudzynski, B., and Hölter, K. 1998. Gibberellin Biosynthetic pathway in Gibberella fujikuroi: Evidence for a gene cluster. Fungal Genet. Biol. 25: 157-170.

Tudzynski, B., Homann, V., Feng, B., and Marzluf, G. A. 1999. Isolation, characterization and disruption of the areA nitrogen regulatory gene of Gibberella fujikuroi. Mol. Gen. Genet. 261:106-114.

Urbaniak, C., Dadwal, S., Bagramyan, K., and Venkateswaran, K. 2018. Draft genome sequence of a clinical isolate of Fusarium fujikuroi isolated from a male patient with acute myeloid leukemia. Genome Announc. 6: e00476-18.

Wasmann, C. C., and VanEtten, H. D. 1996. Transformation-mediated chromosome loss and disruption of a gene for pisatin demethylase decrease the virulence of Nectria haematococca on pea. Mol. Plant-Microbe Interact. 9: 793-803.

Wiemann, P., Sieber, C. M., Von Bargen, K. W., Studt, L., Niehaus, E. M., Espino, J. J., Huß, K., Michielse, C. B., Albermann, S., Wagner, D., and Bergner, S. V. 2013. Deciphering the cryptic genome: Genome-wide analyses of the rice pathogen Fusarium fujikuroi reveal complex regulation of secondary metabolism and novel metabolites. PLoS Pathog 9: e1003475.

Wulff, E. G., Sørensen, J. L., Lübeck, M., Nielsen, K. F., Thrane, U., and Torp, J. 2010. Fusarium spp. associated with rice bakanae: Ecology, genetic diversity, pathogenicity and toxigenicity. Environ. Microbiol. 12: 649-657. 


\section{ERRATUM / Volume 110, Number 3, 2020 / PHYTO-09-19-0359-R}

In the article "Different Phenotypes, Similar Genomes: Three Newly Sequenced Fusarium fujikuroi Strains Induce Different Symptoms in Rice Depending on Temperature" by E. Piombo, P. Bosio, A. Acquadro, P. Abbruscato, and D. Spadaro, the below text, from page 660, referring to an analysis about gene prediction on the de novo assembly has been removed because the analysis has not been included in this paper.

By using MAKER on the de novo assemblies of the three strains, it was possible to observe that the genes of these clusters did not appear to be in a different order in the genomes. However, the short length of the de novo assembly scaffolds made it impossible to verify the position of every gene of the clusters. 